\title{
Evaluasi Kegiatan Utama Pelayanan Posyandu di Kecamatan Jatinangor
}

\author{
Regina Chintya Fani ${ }^{1}$, Sefita Aryuti Nirmala ${ }^{2}$, R. Tina Dewi Judistiani² \\ ${ }^{1}$ Program Diploma Kebidanan, Fakultas Kedokteran Universitas Padjadjaran \\ ${ }^{2}$ Departemen Ilmu Kesehatan Masyarakat, Fakultas Kedokteran Universitas Padjadjaran
}

\begin{abstract}
Abtrak
Posyandu adalah Pos Pelayanan Terpadu yang merupakan bentuk peran serta masyarakat dalam bidang kesehatan yang dibentuk oleh dan untuk masyarakat itu sendiri. Pelayanan Posyandu dilaksanakan kader dan saat ini seluruh desa di wilayah Provinsi Jawa Barat telah memiliki kader kesehatan, hanya saja dalam pelaksanaannya masih terdapat kegiatan utama pelayanan Posyandu yang tidak dilaksanakan. Tujuan penelitian ini adalah untuk mengetahui gambaran kegiatan utama pelayanan di Posyandu Kecamatan Jatinangor. Metode penelitian ini menggunakan metode observasional bersifat kuantitatif dengan pendekatan potong lintang. Penelitian dilaksanakan di Posyandu pada tanggal 05 Agustus - 20 Agustus 2016. Pengumpulan data dilakukan dengan menggunakan daftar tilik dan teknik Consecutive Sampling yang berjumlah 14 Posyandu dari 10 Desa di Kecamatan Jatinangor dan menggunakan analisis univariat. Hasil penelitian menunjukkan 15,9\% ibu hamil yang periksa mendapatkan pelayanan yang dibutuhkan, 27,8\% pelayanan ibu nifas yang diberikan, $69,3 \%$ bayi balita yang diperiksa mendapatkan pelayanan yang dibutuhkan, konseling akseptor KB dilaksanakan 1,1\%, kegiatan imunisasi tidak dilaksanakan, 23,9\% pelayanan gizi tidak dilaksanakan dan $0,31 \%$ pemberian oralit yang dilaksanakan. Simpulan penelitian ini adalah kegiatan utama pelayanan Posyandu masih belum terlaksana dengan baik, sehingga masih perlu evaluasi dan tindak lanjut secara berkala terhadap kegiatan utama yang telah dikerjakan di posyandu.
\end{abstract}

Kata Kunci : Kegiatan utama, Pelayanan, Posyandu

\section{Evaluation of the Main Services of Posyandu in Jatinangor Districts}

\begin{abstract}
Abtract
Posyandu, as a form of community's participation in health service, is organized by and for the community itself. All villages in West Java Province have Kader who help the activities in Posyandu. This is an indication of high participation of people in the community. Unfortunately, there are still problems in the implementation, some main activities are not properly done. The purpose of the study is to know the description of the main activity of Posyandu in Jatinangor district. The research method was observational method with quantitative mature and used cross sectional approach. The research was conducted in Posyandu from August 5-20, 2016. Data collection was performed using checklists and consecutive sampling techniques. This data collection includes 14 Posyandu's in 10 villages at Jatinangor district and using univariate analysis. Only 15.9\% of pregnant women who came check for the services, did received the required service; $27.8 \%$ of postpartum mothers did not get examination; only $40 \%$ of counseling activities were undertaken; only $69.3 \%$ of infants under five who come check to get service needed, counseling on family planning acceptors should be performed only 1.1\%, the required immunization activities are not done, $23.9 \%$ growth abnormality detection nutritional services needed are not done and $0.31 \%$ oralit giving is done from the service of prevention and management of diarrhea. The main activity of Posyandu services are still not performing well, so it is still necessary to evaluate and follow up regularly on the main activity that has been done in the Posyandu.
\end{abstract}

Keywords : Main activity, Posyandu, Service

\footnotetext{
Korespondensi:

Regina Chintya Fani

Program Studi Diploma Kebidanan, Fakultas Kedokteran Universitas Padjadjaran

Jl. Bandung - Sumedang KM. 21 Jatinangor

Mobile : 081802202208

Email : phimexindo@yahoo.com
} 


\section{Pendahuluan}

Sasaran pembangunan kesehatan yang akan dicapai pada tahun 2025 adalah meningkatnya derajat kesehatan masyarakat yang ditunjukkan oleh meningkatnya Umur Harapan Hidup, menurunnya Angka Kematian Bayi, menurunnya Angka Kematian Ibu, menurunnya prevalensi gizi kurang pada balita. Untuk mencapai tujuan dan sasaran pembangunan kesehatan, maka strategi pembangunan kesehatan 2005- 2025 adalah Pembangunan nasional berwawasan kesehatan; Pemberdayaan masyarakat dan daerah; Pengembangan upaya dan pembiayaan kesehatan; Pengembangan dan pemberdayaan sumber daya manusia kesehatan; dan Penanggulangan keadaan darurat kesehatan. ${ }^{1}$

Kesehatan merupakan hak azasi (UUD 1945, pasal28 Hayat 1 danUUNo.36 Tahun2009 tentang Kesehatan) dan sekaligus sebagai investasi, sehingga perlu diupayakan, diperjuangkan dan ditingkatkan oleh setiap individu dan oleh seluruh komponen bangsa, agar masyarakat dapat menikmati hidup sehat, dan pada akhirnya dapat mewujudkan derajat kesehatan masyarakat yang optimal. Hal ini perlu dilakukan karena kesehatan bukanlah tanggung jawab pemerintah saja, namun merupakan tanggung jawab bersama pemerintah dan masyarakat, termasuk swasta. ${ }^{4}$

Salah satu bentuk peran serta masyarakat dalam bidang kesehatan adalah Pos Pelayanan Terpadu (Posyandu) yang dibentuk oleh dan untuk masyarakat itu sendiri. Posyandu merupakan salah satu upaya pelayanan kesehatan yang dikelola oleh masyarakat dengan dukungan teknis petugas puskesmas. Kegiatan Posyandu meliputi 5 program pelayanan kesehatan dasar, yaitu Kesehatan Ibu dan Anak (KIA), Imunisasi, Keluarga Berencana (KB), perbaikan gizi dan penanggulangan diare. ${ }^{2}$

Posyandu merupakan salah satu bentuk Upaya Kesehatan Bersumber Daya Masyarakat (UKBM) yang dikelola dan diselenggarakan dari, oleh, untuk dan bersama masyarakat dalam penyelenggaraan pembangunan kesehatan, guna memberdayakan masyarakat dan memberikan kemudahan kepada masyarakat dalam memperoleh pelayanan kesehatan dasar, utamanya untuk mempercepat penurunan angka kematian ibu dan bayi. ${ }^{4}$

Perkembangan jumlah Posyandu secara kuantitas sangat menggembirakan, karena di setiap desa ditemukan sekitar 3-4 Posyandu. Pada saat Posyandu dicanangkan tahun 1986, jumlah Posyandu tercatat sebanyak 25.000 Posyandu, dan pada tahun 2009, meningkat menjadi 266.827 Posyandu dengan rasio 3,55 Posyandu per desa/kelurahan. Jumlah Posyandu yang tercatat di Provinsi Jawa Barat Tahun 2016 sebanyak 1050 Posyandu dengan rasio 0,66 per 30.000 penduduk. ${ }^{4}$ Hasil analisis Profil Upaya Kesehatan Bersumberdaya Masyarakat (UKBM) menunjukkan pergeseran tingkat perkembangan Posyandu. Jika pada tahun 2001, tercatat $44,2 \%$ Posyandu strata pratama, $34,7 \%$ Posyandu strata madya, serta 18,0\% Posyandu tergolong strata purnama. Maka pada tahun 2003 tercatat 37,7\% Posyandu tergolong dalam strata pratama, $36,6 \%$ Posyandu tergolong strata madya, serta $21,6 \%$ Posyandu tergolong strata purnama. Sementara jumlah Posyandu yang tergolong mandiri meningkat dari 3,1\% pada tahun 2001 menjadi $4,82 \%$ pada tahun $2003 .{ }^{4}$

Seluruh desa di wilayah Provinsi Jawa Barat telah memiliki kader kesehatan dalam membantu menjalani kegiatan pelayanan Posyandu, data ini menunjukkan bahwa sebenarnya peran serta masyarakat dalam bidang kesehatan sudah sangat baik, hanya saja dalam pelaksanaannya masih terdapat kegiatan utama pelayanan Posyandu yang tidak dikerjakan. Jika dilihat dari data di atas, maka perlu ditinjau kembali mengenai pelaksanaan kegiatan utama pelayanan Posyandu. ${ }^{3}$

Berdasarkan studi pendahuluan yang telah dilakukan oleh peneliti di Desa Cipacing dan Desa Cilayung, masih ada Posyandu yang belum dapat menjalankan semua kegiatan yang menjadi kegiatan utama. Jumlah Posyandu dari 12 desa di Kecamatan Jatinangor ada 133 Posyandu. Berdasarkan penjelasan diatas, maka peneliti tertarik untuk mengadakan penelitian tentang evaluasi kegiatan utama pelayanan Posyandu di Kecamatan Jatinangor.

\section{Metode}

Penelitian ini menggunakan jenis penelitian observasional dengan pendekatan potong lintang. Seluruh kegiatan bidan pembina Posyandu pada periode observasi, diambil sebagai sampel secara berurutan (consecutive sampling) sehingga dalam 1 hari didapatkan 1 Posyandu. Terdapat 14 Posyandu yang melakukan kegiatan di awal pagi hari. Sisanya sebanyak 119 Posyandu tidak dapat diamati karena keterbatasan waktu dan jarak. Penelitian ini dimulai dari tanggal 05 Agustus 20 Agustus 2016.

Populasi sampel berjumlah 133 Posyandu. Posyandu yang didapat berjumlah 14, yaitu Desa Sayang RW 5, Desa Cikeruh RW 9, Desa Cipacing RW 8, Desa Cibeusi RW 9, Desa Hegarmanah RW 3, Desa Mekargalih RW 7, Desa Mekargalih RW 2, Desa Cileles RW 7, Desa Jatimukti RW 5, Desa Cintamulya RW 5, Desa Cintamulya RW 7, Desa Cipacing RW 4, Desa Cisempur RW 11 
dan Desa Cipacing RW 3. Subjek pada penelitian adalah bidan pembina Posyandu di Kecamatan Jatinangor dan pelayanan kegiatan utama dari setiap Posyandu di Kecamatan Jatinangor.

Kriteria inklusi pada penelitian ini adalah bidan pembina Posyandu yang melaksanakan kegiatan Posyandu dari tanggal 05 Agustus 2016 - 20 Agustus 2016 di 14 desa, sedangkan kriteria eksklusi pada penelitian ini adalah Bidan tidak di tempat atau tidak dapat dihubungi. Desa yang bersangkutan adalah Desa Cilayung dan Desa Jatiroke. Analisis data pada penelitian ini menggunakan analisis univariat.

Penelitian ini telah mendapatkan persetujuan dari Komite Etik Penelitian Kesehatan Universitas Padjajaran Fakultas Kedokteran. Pada penelitian ini kegiatan utama yang akan di evaluasi adalah Kesehatan Ibu dan Anak (KIA) yang meliputi, pemeriksaan ibu hamil, pelayanan ibu nifas dan menyusui serta pemeriksaan bayi dan balita, kemudian pelayanan Keluarga Berencana (KB), pelayanan imunisasi, pelayanan gizi serta pencegahan dan penanggulangan diare.

\section{Hasil}

Target cakupan ibu hamil di 14 Posyandu Kecamatan Jatinangor adalah 63 orang. Ibu hamil yang paling banyak datang periksa adalah Desa Cibeusi RW 9 yaitu dari jumlah ibu hamil 1 orang yang datang adalah $1(100 \%)$ dan Desa Hegarmanah RW 3 yaitu dari jumlah 1 orang ibu hamil yang datang periksa adalah $1(100 \%)$ dan ibu hamil yang paling banyak tidak datang adalah Desa Sayang RW 5 dari jumlah 2 orang ibu hamil, Desa Cikeruh RW 9 dari jumlah 6 orang ibu hamil, Desa Mekargalih RW 7 dari jumlah 3 orang ibu hamil, Desa Mekargalih RW 2 dari jumlah 3 orang ibu hamil, Desa Cileles RW 7 dari jumlah 2 oarang ibu hamil, Desa Cintamulya RW 5 dari jumlah 9 orang ibu hamil dan Desa Cintamulya RW 7 dari jumlah 2 orang ibu hamil.

Berdasarkan tabel 1. menunjukkan bahwa kegiatan pemeriksaan ibu hamil yang tidak dibutuhkan dan tidak dikerjakan adalah pemberian imunisasi Tetanus Toxoidsehingga tidakdianalisis.

Target cakupan ibu nifas di 14 Posyandu Kecamatan Jatinangor adalah 18 orang. Pada tabel tersebut didapatkan bahwa tidak ada ibu nifas yang datang periksa ke Posyandu. Ibu nifas yang paling banyak tidak datang adalah Desa Cipacing RW 8 dari jumlah 1 orang, Desa Cibeusi RW 9 dari jumlah 1 orang, Desa Mekargalih RW 2 dari jumlah 1 orang, Desa Cileles RW 7 dari jumlah 1 orang, Desa Jatimukti RW 5 dari jumlah 3 orang, Desa Cintamulya RW 5 dari jumlah 1 orang dan Desa Cipacing RW 4 dari jumlah 2 orang.

Tabel 1 Distribusi Frekuensi Kegiatan Pelayanan Kesehatan Ibu dan Anak (KIA) Mengenai Pemeriksaan Ibu Hamil di 14 Posyandu Kecamatan Jatinangor

\begin{tabular}{|c|c|c|c|c|}
\hline No & $\begin{array}{c}\text { Kegiatan Pemeriksaan } \\
\text { Ibu Hamil }\end{array}$ & $\begin{array}{l}\text { Jumlah Pelayanan } \\
\text { yang dibutuhkan }\end{array}$ & & \\
\hline & & f & f & $\%$ \\
\hline 1 & Pengukuran Berat Badan & 15 & 11 & 73,3 \\
\hline 2 & Pengkuran Tinggi Badan & 15 & 10 & 66,7 \\
\hline 3 & Pengukuran Tekanan Darah & 15 & 10 & 66,7 \\
\hline 4 & $\begin{array}{l}\text { Pemantauan nilai status gizi } \\
\text { (pengukuran lingkar lengan } \\
\text { atas) }\end{array}$ & 15 & 6 & 40 \\
\hline 5 & Pemberian tablet $\mathrm{Fe}$ & 15 & 8 & 53,3 \\
\hline 6 & $\begin{array}{l}\text { Pemberian imunisasi Tetanus } \\
\text { Toxoid }\end{array}$ & 0 & 0 & 0 \\
\hline 7 & $\begin{array}{l}\text { Pengukuran Tinggi Fundus } \\
\text { Uteri }\end{array}$ & 15 & 6 & 40 \\
\hline 8 & $\begin{array}{l}\text { Konseling, termasuk } \\
\text { Perencanaan Persalinan dan } \\
\text { Pencegahan Komplikasi } \\
\text { (P4K) serta KB pasca } \\
\text { persalinan }\end{array}$ & 15 & 10 & 66,7 \\
\hline 9 & Kelas ibu hamil & 0 & 0 & 0 \\
\hline
\end{tabular}


Tabel 2 Distribusi Frekuensi Kegiatan Pelayanan Kesehatan Ibu dan Anak (KIA) Mengenai Pelayanan Ibu Nifas dan Menyusui di 14 Posyandu Kecamatan Jatinangor

\begin{tabular}{llllc}
\hline No & $\begin{array}{c}\text { Kegiatan Pelayanan Ibu Nifas dan } \\
\text { Menyusui }\end{array}$ & $\begin{array}{c}\text { Jumlah Pelayanan } \\
\text { yang dibutuhkan }\end{array}$ & \multicolumn{2}{c}{ Capaian } \\
\hline & f & f & \% \\
\hline 1 & $\begin{array}{l}\text { Pemeriksaan kesehatan umum, } \\
\text { pemeriksaan payudara, tinggi fundus }\end{array}$ & 5 & 0 & 0 \\
& uteri, lochea & & & \\
2 & Pemberian 2 kapsul vitamin A & 0 & 0 & 0 \\
3 & Perawatan payudara & 5 & 0 & 0 \\
4 & $\begin{array}{l}\text { Penyuluhan/konseling kesehatan, KB } \\
\text { pasca persalinan, Inisiasi Menyusu }\end{array}$ & 5 & 2 & 40 \\
& Dini (IMD), ASI Eksklusif dan gizi & & & \\
\hline
\end{tabular}

Tabel 3 Distribusi Frekuensi Kegiatan Pelayanan Kesehatan Ibu dan Anak (KIA) Mengenai Pemeriksaan Bayi dan Balita di 14 Posyandu Kecamatan Jatinangor

\begin{tabular}{llccc}
\hline No & $\begin{array}{c}\text { Kegiatan Pemeriksaan } \\
\text { dan Balita }\end{array}$ & $\begin{array}{c}\text { Jumlah Pelayanan } \\
\text { yang dibutuhkan }\end{array}$ & Capaian & \\
\hline & & f & f & \% \\
\hline 1 & Penimbangan Berat Badan & 640 & 640 & 100 \\
2 & Penentuan status pertumbuhan & 640 & 640 & 100 \\
3 & $\begin{array}{l}\text { Deteksi dini tumbuh kembang } \\
\text { (SDIDTK) }\end{array}$ & 158 & 0 & 0 \\
4 & Penyuluhan dan konseling & 640 & 640 & 100 \\
\hline
\end{tabular}

Tabel 4 Distribusi Frekuensi Kegiatan Pelayanan Keluarga Brencana (KB) di 14 Posyandu Kecamatan Jatinangor

\begin{tabular}{llccc}
\hline No & $\begin{array}{c}\text { Kegiatan Pelayanan Keluarga } \\
\text { Berencana (KB) }\end{array}$ & $\begin{array}{c}\text { Jumlah Pelayanan } \\
\text { yang dibutuhkan }\end{array}$ & Capaian & \\
\hline & & f & f & \% \\
\hline 1 & Pemberian kondom & 0 & 0 & 0 \\
2 & Pemberian pil ulangan & 0 & 0 & 0 \\
3 & KB suntik & 0 & 0 & 0 \\
4 & Implant dan IUD & 0 & 0 & 0 \\
5 & Konseling KB & 50 & 6 & 12 \\
\hline
\end{tabular}

Berdasarkan tabel 2. menunjukkan bahwa kegiatan pelayanan pada ibu nifas dan meyusui yang tidak dibutuhkan dan tidak dikerjakan adalah pemberian 2 kapsul vitamin A yaitu sebanyak $5(100 \%)$.

Target cakupan bayi dan balita di 14 Posyandu Kecamatan Jatinangor adalah 924 orang. Bayi dan balita yang paling banyak datang periksa adalah Desa Mekargalih RW 7 yaitu dari jumlah 19 bayi dan balita yang datang periksa adalah 19 $(100 \%)$, bayi dan balita yang paling banyak tidak datang adalah Desa Mekargalih RW 2 dari jumlah 75 bayi dan balita yang datang hanya 36 (48\%).
Dari tabel 3. menunjukkan bahwa kegiatan pemeriksaan bayi dan balita yang dibutuhkan dan tidak dikerjakan adalah deteksi dini tumbuh kembang (SDIDTK) yaitu sebanyak $158(24,7 \%)$.

Target Cakupan Akseptor KB jangka pendek di 14 Posyandu Kecamatan Jatinangor adalah 1635 orang. Berdasarkan observasi di dapatkan bahwa tidak ada akseptor KB jangka pendek yang periksa ke Posyandu, kemudian target cakupan akseptor KB jangka panjang dari 14 Posyandu adalah 348 orang. Berdasarkan hasil observasi didapatkan bahwa tidak ada akseptor KB jangka panjang yang periksa ke Posyandu. 
Tabel 5 Distribusi Frekuensi Kegiatan Pelayanan Imunisasi di 14 Posyandu Kecamatan Jatinangor

\begin{tabular}{llccc}
\hline No & \multicolumn{1}{c}{$\begin{array}{c}\text { Kegiatan Pelayanan } \\
\text { Imunisasi }\end{array}$} & $\begin{array}{c}\text { Jumlah Pelayanan } \\
\text { yang dibutuhkan }\end{array}$ & Capaian & \\
\hline & & f & f & $\%$ \\
\hline 1 & Imunisasi HB0 & 0 & 0 & 0 \\
2 & Imunisasi BCG & 4 & 0 & 0 \\
3 & Imunisasi Polio & 95 & 0 & 0 \\
4 & Imunisasi DPT Pentabio & 31 & 0 & 0 \\
5 & Imunisasi Campak & 60 & 0 & 0 \\
\hline
\end{tabular}

Tabel 6 Distribusi Frekuensi Kegiatan Pelayanan Pencegahan dan Penanggulangan Diare di 4 Posyandu Kecamatan Jatinangor

\begin{tabular}{llccc}
\hline No & $\begin{array}{l}\text { Kegiatan Pelayanan Pencegahan } \\
\text { dan Penanggulangan Diare }\end{array}$ & $\begin{array}{c}\text { Jumlah Pelayanan } \\
\text { yang dibutuhkan }\end{array}$ & & Capaian \\
\hline & & f & f & \% \\
\hline 1 & $\begin{array}{l}\text { Penyuluhan Perilaku Hidup } \\
\text { Bersih dan Sehat (PHBS) }\end{array}$ & 0 & 0 & 0 \\
2 & Pemberian Oralit & 2 & 2 & 100 \\
\hline
\end{tabular}

Dari tabel 4. menunjukkan bahwa kegiatan pelayanan KB yang dibutuhkan dan dikerjakan adalah konseling KB yaitu sebanyak 6 (12\%), sedangkan yang tidak dikerjakan yaitu sebanyak $44(88 \%)$.

Berdasarkan tabel 5. menunjukkan bahwa kegiatan pelayanan imunisasi yang dibutuhkan dan tidak dikerjakan adalah BCG 4 (0,63\%), imunisasi polio $95(14,8 \%)$, imunisasi DPT pentabio 31 $(4,84 \%)$ dan imunisasi campak $60 \quad(9,38 \%)$.

Berdasarkan tabel 6. menunjukkan bahwa kegiatan pencegahan dan penanggulangan diare yang dibutuhkan dan dikerjakan adalah pemberian oralit yaitu sebanyak $2(100 \%)$.

\section{Pembahasan}

Kegiatan Pelayanan Kesehatan Ibu dan Anak (KIA) Mengenai Pemeriksaan Ibu Hamil; Berdasarkan target cakupan ibu hamil di 14 Posyandu dari 63 ibu hamil yang datang periksa sebanyak $10(15,9 \%)$. Hal ini karena ibu hamil sadar akan kebutuhan pemeriksaan kehamilan dan bidan desa juga memfasilitasi untuk pemeriksaan ibu hamil dengan membawa alat pemeriksaan kehamilan dan memberikan konseling sesuai dengan kebutuhan ibu hamil. Pemberian imunisasi TT yang tidak dibutuhkan dan tidak dikerjakan karena ibu hamil yang datang ke Posyandu sudah mendapatkan imunisasi TT. Berdasarkan hasil observasi, Ibu hamil yang datang ke Posyandu rata-rata berusia kehamilan di atas 5 bulan, sehingga imunisasi TT sudah dilaksanakan. Imunisasi TT ini sangat diperlukan bagi ibu hamil. Terdapat $76 \%$ ibu hamil yang tidak mengetahui dari pentingnya pemberian imunisasi TT, sehingga diperlukan penyuluhan bagi ibu hamil. Menurut penelitian dari Syarifah pada tahun 2012 yaitu tentang faktor-faktor yang mempengaruhi cakupan imunisasi tetanus toxoid pada ibu hamil didapatkan bahwa adanya pengaruh pengetahuan dengan pemberian imunisasi TT pada ibu hamil. Pengetahuan yang didapatkan bisa dari penyuluhan, brosur, teman, dan semakin banyak pengetahuan yang di dapatkan maka semakin besar kemungkinan untuk melakukan imunisasi TT. ${ }^{7}$ Kelas ibu hamil yang tidak dibutuhkan dan tidak dikerjakan karena pelaksanaan kelas ibu hamil sudah tidak dikerjakan pada bulan Agustus. Kelas ibu hamil yang diselenggarakan di Posyandu hanya dikerjakan sebanyak 2 kali dalam 1 tahun, kelas ibu hamil berikutnya akan diselenggarakan antara bulan September dan Oktober. Pentingnya diadakan kelas ibu hamil untuk meningkatkan pengetahuan dan keterampilan ibu mengenai kehamilan, perawatan kehamilan, persalinan, perawatan nifas, perawatan bayi baru lahir, mitos, penyakit menular dan akte kelahiran. ${ }^{8}$

Kegiatan Pelayanan Kesehatan Ibu dan Anak (KIA) Mengenai Pelayanan Ibu Nifas dan Menyusui; Berdasarkan target cakupan ibu nifas di 14 Posyandu dari 18 ibu nifas yang datang periksa berjumlah $0(0 \%)$. Hal ini karena ibu nifas tidak 
ingin memeriksakan dirinya, selain itu bidan juga tidak memfasilitasi untuk memberikan pelayanan pada ibu nifas dan menyusui. Pemberian kapsul vitamin A tidak dibutuhkan dan dikerjakan karena pemberian kapsul vitamin A sudah diberikan di tempat bersalin ibu. Pemberian konseling dikerjakan sebanyak 2 (40\%), kegiatan ini hanya dikerjakan pada 2 ibu nifas di Desa Sayang dan tidak dikerjakan desa lain dikarenakan bidan tidak memfasilitasi pelayanan pemeriksaan pada ibu nifas. Menurut penelitian dari Islami pada tahun 2011 yaitu tentang efektivtas kunjungan nifas terhadap pengurangan ketidaknyamanan fisik yang terjadi pada ibu selama masa nifas didapatkan bahwa Sebanyak $76 \%$ wanita mengalami sedikitnya satu masalah kesehatan 8 minggu setelah melahirkan. ${ }^{9}$ Cakupan pelayanan nifas pada tahun 2009 mengalami penurunan. Oleh karena itu pemeriksaan pada ibu nifas sangat diperlukan. ${ }^{10}$

Kegiatan Pelayanan Kesehatan Ibu dan Anak (KIA) Mengenai Pemeriksaan Bayi dan Balita; Berdasarkan target cakupan bayi dan balita di 14 Posyandu dari 924 bayi dan balita yang datang periksa sebanyak $640(69,3 \%)$. Hal ini karena ibu bayi dan balita sadar akan kebutuhan pemeriksaan bayi dan balita di Posyandu. Kegiatan SDIDTK tidak dikerjakan dikarenakan pada bulan Agustus hanya berfokus pada pemberian vitamin A, sedangkan untuk pemeriksaan SDIDTK akan dikerjakan pada bulan September atau akhir bulan Agustus setelah kegiatan Posyandu selesai. Kegiatan SDIDTK ini kurang berjalan dengan baik dan kadang di anggap hal yang mudah. Penelitian ini sejalan dengan penelitian yang dilakukan oleh Seodjatmiko yang mengatakan bahwa pemeriksaan SDIDTK menggunakan kuesioner KPSP yang biasanya digunakan di tingkat pelayanan primer, tetapi tampaknya jarang di manfaatkan. ${ }^{11}$

Kegiatan Pelayanan Keluarga Brencana (KB); Berdasarkan target cakupan akseptor KB di 14 Posyandu dari 1635 akseptor KB, tidak ada akseptor KB yang datang periksa. Hal ini karena ibu tidak memiliki kebutuhan pada saat itu. Ibu yang datang membawa bayi atau balitanya ke Posyandu sudah mendapatkan pelayanan KB sebelumnya atau ibu yang belum saatnya mendapatkan pelayanan $\mathrm{KB}$ berikutnya dan terdapat pula ibu yang tidak ingin mendapatkan pelayanan KB jangka pendek dan panjang di Posyandu. Kegiatan pelayanan $\mathrm{KB}$ yang dikerjakan hanya konseling KB. Berdasarkan observasi peneliti, Konseling KB hanya dikerjakan oleh Desa Sayang dan Cibeusi dikarenakan pasien menanyakan kebutuhannya kepada bidan, sedangkan pada Desa lain pasien banyak yang tidak ingin dan tidak merasa butuh untuk melakukan konseling KB dengan bidan. Penelitian ini sejalan dengan penelitian yang dilakukan oleh Siswanto, menemukan bahwa untuk kegiatan $\mathrm{KB}$, KIA, penanggulangan diare tidak berjalan $100 \%$, karena kebanyakan bidan desa menganjurkan periksa di Polindes. ${ }^{5}$

Kegiatan Pelayanan Imunisasi; Berdasarkan hasil penelitian, capaian imunisasi tidak sesuai dengan harapan. Kegiatan ini tidak dikerjakan karena pada saat Posyandu sedang berlangsung tidak sesuai dengan jadwal imunisasi bayi, selain itu ibu lebih memilih melakukan imunisasi di luar pelayanan Posyandu. Beberapa desa seperti Desa Sayang, Cikeruh, Cileles, Hegarmanah dan Cisempur tidak membawa vaksin BCG, DPT pentabio, polio dan campak ke Posyandu. Jika ingin melakukan imunisasi pasien disarankan untuk datang ke Poskesdes, Pustu atau PKM. Menurut penelitian dari Vivi pada tahun 2015 yaitu tentang faktor yang berhubungan dengan pemberian imunisasi dasar lengkap pada bayi didapatkan bahwa hambatan orang tua tidak menjadi faktor yang berhubungan dengan kelengkapan imunisasi, hal ini terjadi karena sebagian besar orang tua tidak mengalami kesulitan/hambatan dalam pemberian imunisasi dasar lengkap pada anaknya seperti hambatan jarak yang jauh ke pelayanan imunisasi, waktu imunisasi, ketersediaan vaksin, masalah keluarga, masalah anak itu sendiri, waktu tunggu yang lama dan alasan biaya imunisasi. Anak yang mendapatkan dan tidak mendapatkan imunisasi dasar lengkap sama-sama tidak mengalami kesulitan/hambatan dalam mendapatkan imunisasi. ${ }^{12}$

Kegiatan Pelayanan Pencegahan dan Penanggulangan Diare; Berdasarkan capaian terhadap kegiatan pelayanan pencegahan dan penanggulangan diare didapatkan setiap petugas kesehatan di Posyandu menyediakan oralit bagi pasien yang membutuhkan. Berdasarkan hasil observasi, terdapat satu Posyandu di Desa Cipacing Rw 08 yang melayani pemberian oralit karena terdapat 2 orang balita yang sedang diare. Kegiatan PHBS di Posyandu dikerjakan oleh petugas khusus PHBS yang biasanya dikerjakan satu tahun 2 kali oleh petugas PHBS.

Penelitian ini sejalan dengan penelitian yang dilakukan oleh Suryani, menemukan bahwa dalam pelaksanaannya penyuluhan sewajarnya dilakukan setiap selesai dilakukan penimbangan, namun pada kenyataannya banyak petugas atau kader tidak melakukannya. ${ }^{6}$

Simpulan pada penelitian ini adalah bahwa kegiatan utama pelayanan Posyandu masih belum terlaksana dengan baik, sehingga masih perlu evaluasi dan tindak lanjut secara berkala terhadap kegiatan utama yang telah dikerjakan di 
posyandu. Mendukung kegiatan utama posyandu yang belum dilaksanakan baik yaitu Kesehatan Ibu dan Anak (KIA) yang meliputi, pemeriksaan ibu hamil, pelayanan ibu nifas dan menyusui serta pemeriksaan bayi dan balita, kemudian pelayanan Keluarga Berencana (KB), pelayanan imunisasi, pelayanan gizi serta pencegahan dan penanggulangan diare, kemudian dukungan SDM, sarana prasarana atau bantuan dana melalui advokasi lintas sektor.

Saran untuk penelitian ini adalah Puskesmas disarankan melakukan evaluasi dan tindak lanjut secara berkala terhadap kegiatan utama yang telah dikerjakan di posyandu mendukung kegiatan utama posyandu yang belum dilaksanakan dengan baik yaitu berupa dukungan SDM, sarana prasarana atau bantuan dana melalui advokasi lintas sektor. Bidan desa disarankan memberikan jadwal pelayanan; seperti pelayanan ibu nifas dan menyusui, pelayanan imunisasi, dilihat berdasarkan kebutuhan pasien, agar cakupan kegiatan utama dapat terlaksana dengan baik. Selanjutnya, pelaksanaan kegiatan SDIDTK dapat dikerjakan pada bulan selanjutnya dan dapat dilaksanakan sesuai dengan usia KPSP yang telah ada.

Keterbatasan peneliti dalam penelitian ini adalah peneliti mengamati kegiatan Posyandu di pagi hari saat kegiatan Posyandu sedang berjalan, Posyandu yang dapat diamati hanya berjumlah satu dalam sehari. Total Posyandu yang bisa peneliti dapatkan selama batas waktu yang ditentukan berjumlah 14 Posyandu. Hal ini dikarenakan adanya keterbatasan waktu dan jarak yang di tempuh oleh peneliti.

\section{Daftar Pustaka}

1. RI KK. Rencana strategis kementerian kesehatan tahun 2015-2019. Jakarta. 2015. p. 41.

2. RI D. Pedoman untuk pengelolaan posyandu.
In: Depkes, editor. Jakarta; 2006.

3. RI KK. Assessment GAVI - HSS 2010-2011 direktorat jenderal bina gizi dan KIA : laporan akhir provinsi jawa barat. In: Direktorat Jenderal Bina Gizi dan Kesehatan Ibu dan Anak GA, editor. Jakarta: Kementerian Kesehatan RI; 2011. p. 33-7.

4. RI KK. Pedoman umum pengelolaan posyandu. Jakarta: Kementrian Kesehatan RI; 2011

5. Siswanto. Evaluasi kegiatan posyandu di kabupaten , bojonegro, jombang, sikka dan cianjur.; 2007. P. 307-308 http://ejournal. litbang.depkes.go.id/index.php/hsr/article/ view/1712. Diakses pada 31 Juli 2016

6. Suryani. Gambaran kegiatan posyandu dan status gizi balita di wilayah kerja Puskesmas Silih Nara Kabupaten Aceh Tengah tahun 2012; 2012. P.50. lib.ui.ac.id/ file?file=digital/20317896-S-Suryani.pdf. Diakses pada 01 Agustus 2016.

7. Maulida, Syarifah W. Faktor-faktor mempengaruhi cakupan imunisasi tetanus toxoid pada ibu hamil. Jurnal Kesehatan. 2012;7-8

8. Faunda N. Pelaksanaan kelas ibu hamil di indonesia; 2015. P.2. http://ejournal.litbang. depkes.go.id/index.php/kespro/article/ download/4745/4207 . Diakses pada 29 Juli 2016.

9. Islami, Aisyaroh N. Efektivtas kunjungan nifas terhadap pengurangan ketidaknyamanan fisik yang terjadi pada ibu selama masa nifas. Jurnal Kesehatan. 2011; P.11

10. Sophie Grioradis. Cindylee D. Kenneth F. et al. Postpartum cultural practices: a systematic review of the evidence. BMC. 2008;10.1186

11. Soedjatmiko. Deteksi dini gangguan tumbuh kembang balita. Sari Pediatri. 2006;3.180-81

12. Triana V. Faktor yang berhubungan dengan pemberian imunisasi dasar lengkap pada bayi. Jurnal Kesehatan Masyarakat Andalas (JKMA). 2015;132-33 